\title{
Edward G. Stopa, MD 06 July 1954 - 18 September 2019
}

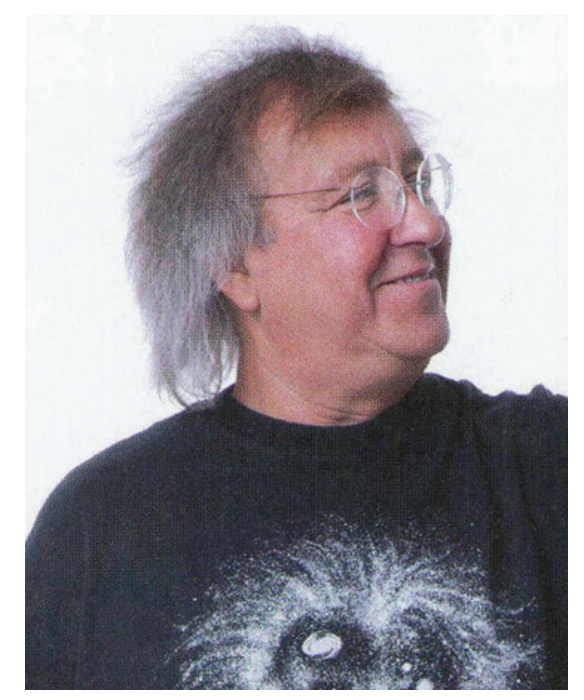

Dr. Edward G. Stopa, neuropathologist, physicianscientist, and clinician, passed away peacefully on Wednesday, 18 September 2019, at 65 years of age after a brief and courageous battle with pancreatic cancer. Ed was born and raised in Newark, NJ. He received his undergraduate degree in physiology in 1976 and medical degree in 1980 from McGill University in Montreal, Canada. He completed his residency in anatomic pathology and fellowship in neuropathology at the Brigham and Women's Hospital in Boston, MA, an affiliate of the Harvard Medical School. In 1985, Ed was appointed Assistant Professor of Pathology at Tufts University School of Medicine. In 1989, he became assistant director of neuropathology and associate professor of pathology at the State University of New York Health Science Center in Syracuse. Then, in 1993, Dr. Stopa was appointed as Associate Professor of Pathology and Laboratory Medicine and Neurosurgery at the Warren Alpert Medical School of Brown University. He also was appointed to the clinical staff at Lifespan's Rhode Island Hospital and Miriam Hospital as Division Director of Neuropathology. In 2002, he was promoted to full professor in the Research Scholar track.

From 1993-2019, Dr. Stopa's main clinical responsibilities included the full range of diagnostic neuropathology, requiring active participation in CNS, nerve, and muscle biopsy interpretations, frozen section diagnoses, and postmortem examinations. In addition, Dr. Stopa oversaw the Brown Brain Bank which provides fresh-frozen and formalin-fixed human brain tissue for neuroscience research, particularly Alzheimer's disease. The bank's uniqueness is attributable to the fact that the postmortem brains were from individuals who had been studied in detail and followed for many years by very talented neurologists and neuropsychologists. Dr. Stopa also served as co-director of the autopsy service and director of the neuropathology fellowship training program and was responsible for training and educating dozens of fellows in neuropathology, as well as residents and fellows in pathology, neurosurgery, neurology, psychiatry, and geriatric psychiatry. Dr. Stopa had major teaching roles in undergraduate neuroscience and medical school neuropathology courses, and he guided and mentored a continuous stream of independent study and research undergraduate, graduate, and medical students from Brown. His vibrant, engaging, entertaining, and enthusiastic teaching style drew scores of students at all levels to brain and neuroscience research.

Throughout his career, Dr. Stopa led independent translational and human research programs and maintained a broad collaborative research network both within and beyond the Brown academic theatre. His research efforts were primarily focused 
on Alzheimer's disease, with particular interests in determining how the blood-brain barrier gets disrupted, identifying the underlying mechanisms of hypothalamic dysfunction linked to impaired circadian rhythm and attendant disordered sleep-wake cycles that plague afflicted individuals early in the course of their disease, and evaluating the role of agrin in the build-up of amyloid deposits in the brain. His scholarly academic accomplishments included publication of over 120 peer-reviewed medical and scientific articles with an $\mathrm{H}$-index of 40 , success in obtaining NIH grant support, participation in national and international scientific grant review, and appointments to medical advisory councils such as the Alzheimer's Association of Rhode Island.

Dr. Stopa will always be remembered for his vibrant personality, his larger-than-life stories that provided entertainment for countless hours, his eccentric clothing style, and his brilliant mind. Although he excelled in his career and research endeavors, Ed's true personal passion was the ocean. He was an enthusiastic scuba diver, sailor, swimmer and beach-goer. He was always last to winterize his sailboat (usually in December) and first to get it back into the water (usually in March). He scubadived to explore wrecks even in the dead of winter and bragged about his experience diving between two tectonic plates off the coast of Iceland. Ed had many stories of sailing deliberately during threats of hurricane-even monitoring the forecast to get out on the ocean, just in time. When he was not on or in the water, Ed enjoyed cycling and skiing and had a passion for astronomy. Ed preferred to cycle at night, claiming it was safer because cars wouldn't be drawn by lights or reflectors to hit him. On some of the coldest days in New England with the ground thoroughly covered in packed snow, Ed sent us photos of himself on a mountain bike in the woods. Ed was fascinated with astronomy. He typically peppered his neuroscience and medical school lectures with images of galaxies and nebulae. Although initially very confusing, the students always warmed up to his sidebar education. He held onto a large old van to transport his telescope. Once at a Neuroscience meeting, he was seen in the convention center lobby recruiting colleagues to join him for an impromptu stargazing trip in the desert. Ed will always be remembered for his storytelling. He really knew how to bring you to the scene of adventure-whether it was the code team who had climbed a flagpole to resuscitate a patient who had fallen from a tall building, or the bidirectional honking celebration precipitated by Ed's urgent need to decompress his bladder after sitting for hours in I-93 traffic on his way to Logan Airport, having drunk a thick pot of Oolong tea just before leaving Providence. No one ever cared about the degree to which his stories were embellished, because they were always funny and a little bit different each time they were told.

Dr. Stopa loved spending time with his family and particularly cherished his role as a grandfather. He is survived by Karen E. (Madras) Stopa, M.D., his wife of 39 years, his daughter Emily and son-in-law John C. MacMillan, Jr. of Chevy Chase, MD, three other daughters, Eliza, Eva, and Arielle, four grandchildren, his sister-in-law, Carol Stopa, his brother-in-law, Mark Madras and wife, Eva Madras, and his two nephews.

A Memorial Service was held for Dr. Stopa on Saturday, September 28, 2019 at Manning Hall, 21 Prospect Street, Providence, RI, followed by a reception at The Brown Faculty Club. The overflowing attendance by faculty, former trainees, students, friends, colleagues, and technical and support staff was a spectacular display of gratitude and reflected the large number and breadth of individuals that were significantly impacted by their experiences and time spent with Dr. Edward G. Stopa.

Suzanne M. de la Monte, MD MPH, E-mail: suzanne_delamonte_md@brown.edu

John E. Donahue, MD

Bassam I. Aswad, MD 